\title{
AVALIAÇÃO DOS CUSTOS OPERACIONAIS EFICIENTES DAS EMPRESAS DE TRANSMISSÃO DO SETOR ELÉTRICO BRASILEIRO: UMA PROPOSTA DE ADAPTAÇÃO DO MODELO DEA ADOTADO PELA ANEEL
}

\author{
José Francisco Moreira Pessanha* \\ Dep. de Estatística / Instituto de Matemática e Estatística \\ Universidade do Estado do Rio de Janeiro (UERJ) \\ Rio de Janeiro - RJ \\ professorjfmp@hotmail.com
}

\author{
Marina Almeida Rego Figueira de Mello \\ Dep. de Economia / Centro de Ciências Sociais \\ Pontifícia Universidade Católica do Rio de Janeiro (PUC-RJ) \\ Rio de Janeiro - RJ \\ marina@econ.puc-rio.br

\section{Mônica Barros \\ Reinaldo Castro Souza} \\ Dep. de Engenharia Elétrica / Centro Técnico-Científico \\ Pontifícia Universidade Católica do Rio de Janeiro (PUC-RJ) \\ Rio de Janeiro - RJ \\ barrosm@alumni.utexas.net \\ reinaldo@ele.puc-rio.br
}

* Corresponding author / autor para quem as correspondências devem ser encaminhadas Recebido em 03/2008; aceito em 11/2009 após 1 revisão Received March 2008; accepted November 2009 after one revision

\section{Resumo}

No setor elétrico brasileiro, as companhias de transmissão são remuneradas pela disponibilidade da capacidade de seus ativos, independentemente da quantidade de energia elétrica transmitida. Para induzir a operação eficiente das transmissoras, a ANEEL deve revisar periodicamente as receitas permitidas das transmissoras, considerando custos operacionais eficientes. Recentemente, a ANEEL publicou uma resolução em que descreve a metodologia utilizada no cálculo dos custos operacionais eficientes das transmissoras, a qual inclui um modelo de análise envoltória de dados (DEA). Neste trabalho propomos uma adaptação deste modelo DEA e apresentamos uma análise de sensibilidade dos resultados obtidos pelos dois modelos.

Palavras-chave: análise envoltória de dados; transmissão de energia elétrica; revisão tarifária.

\begin{abstract}
In the Brazilian power sector, the transmission companies (TRANSCOS) receive revenues by the availability of their transmission facilities, regardless of the amount of the electric power transmitted. To promote their efficient operation the regulator periodically revises the revenue caps. The calculation of efficient operational costs is the first stage of the tariff revision process. Recently, the regulator agent published a resolution describing the methodology used to set the revenues of the Brazilian TRANSCOS. This algorithm includes a data envelopment model (DEA) which is described in this paper. In this work we propose an alternative DEA model and present a comparison of the results obtained by the two models.
\end{abstract}

Keywords: data envelopment analysis; electricity power transmission; tariff revision. 


\section{Introdução}

O transporte de energia elétrica entre as usinas geradoras e os centros de consumo é efetuado pelo sistema de transmissão, uma complexa rede de cabos elétricos, isoladores, torres, transformadores, disjuntores, reatores, bancos de capacitores, ferragens e outros equipamentos. A partir da combinação destes equipamentos são construídas linhas de transmissão e subestações, os elementos básicos de um sistema de transmissão, responsáveis pelo balanço instantâneo de produção e consumo de energia elétrica.

Linhas de transmissão e subestações são ativos com elevados custos fixos irrecuperáveis e que exigem um longo prazo de maturação do investimento. Em razão das economias de escala, a transmissão de energia elétrica é um monopólio natural e, portanto, há necessidade de colocá-la sob as regras de um mecanismo de regulação econômica capaz de simular as condições de um mercado competitivo.

A regulação econômica da transmissão se dá pelo controle da receita das transmissoras. Os ativos de transmissão são remunerados pelas suas disponibilidades, independentemente da utilização plena das suas capacidades, e cada instalação tem direito a uma receita anual permitida (RAP) determinada pela Agência Nacional de Energia Elétrica (ANEEL).

As instalações de transmissão que compõem o Sistema Interligado Nacional (SIN) são classificadas em dois grupos: a rede básica e as demais instalações de transmissão. A rede básica é constituída por instalações de uso compartilhado e por transformadores de potência que operam com tensão igual ou superior a $230 \mathrm{kV}$. As demais instalações de transmissão englobam as instalações com tensão menor que $230 \mathrm{kV}$. A rede básica do SIN foi regulamentada pelo Decreto $\mathrm{n}^{\mathrm{o}} 1.717$, de 24.11.1995 e em dezembro de 2004 atingiu uma extensão de aproximadamente $80.022 \mathrm{~km}$, com 815 circuitos de transmissão e uma capacidade de transformação de 178.447 MVA, distribuída em 321 subestações, conforme consta na Nota Técnica ANEEL nº 068/2006-SRT.

Para fins de remuneração, os ativos de transmissão são classificados como instalações existentes e novas instalações (autorizadas e licitadas). As instalações existentes (da rede básica e demais instalações de transmissão) são listadas na Resolução ANEEL n ${ }^{\circ}$ 166/2000 e compreendem o conjunto de instalações que já se encontravam operando até 31 de dezembro de 1999 . As instalações adicionadas após esta data constituem as novas instalações autorizadas ou licitadas.

As receitas permitidas (RAPs) das instalações existentes foram definidas na Resolução ANEEL n ${ }^{\circ} 167 / 2000$ para as instalações que compõem a rede básica existente (RBSE) e para as instalações de conexão e demais instalações (RPC), estabelecendo-se assim o equilíbrio econômico-financeiro inicial dos contratos. As instalações existentes constituem mais de $80 \%$ do sistema.

As novas instalações autorizadas (NI) são compostas pelos reforços (aumento da capacidade) na rede básica (RBNI) e nas demais instalações de transmissão (RCDM), implantados pelas concessionárias citadas na Resolução ANEEL n 166/2000. As RAPs associadas aos reforços são estabelecidas por resoluções específicas após a publicação da Resolução ANEEL $n^{\circ} 167 / 2000$.

As novas instalações licitadas são outorgadas em leilões, em que os investidores interessados competem pela concessão de novos empreendimentos de transmissão. É declarado vencedor o investidor que aceitar a menor receita anual permitida pela construção e operação do empreendimento de transmissão. 
Recentemente, por meio da Resolução ANEEL no 257 de 6 de março de 2007, foram estabelecidos os conceitos gerais, a metodologia e os procedimentos para a realização da primeira revisão tarifária periódica das concessionárias de transmissão de energia elétrica, cujo principal resultado é o reposicionamento da RAP referente às novas instalações autorizadas. Ressalta-se que as receitas das novas instalações licitadas também estão sujeitas ao processo de revisão tarifária.

A separação entre instalações existentes e novas deve-se a uma cláusula contratual que restringe a revisão das tarifas de transmissão ao âmbito das novas instalações. A origem desta cláusula remonta ao processo de desverticalização do setor elétrico brasileiro (SEB) no final da década de 90 quando as tarifas de suprimento foram desmembradas em tarifa de geração (tarifa dos contratos iniciais) e tarifa de transmissão, esta última obtida pela diferença entre a tarifa de suprimento vigente e a tarifa de geração, para não aumentar a tarifa paga pelo consumidor final.

Naquela época, com o objetivo de tornar a geração de energia elétrica atraente aos investidores privados, a tarifa de transmissão foi subdimensionada, passando a cobrir apenas os custos para manutenção do serviço e não guardando nenhuma relação com o valor dos ativos de transmissão. Para contornar este desequilíbrio, as receitas das instalações existentes são reajustadas automaticamente pelo IGP-M até o ano 2015 (prazo final do contrato de concessão), sem serem submetidas à revisão tarifária. Assim, as concessionárias se apropriam dos ganhos de produtividade destas instalações e podem auferir receitas que compensem as perdas iniciais, restabelecendo o equilíbrio econômico-financeiro da concessão. Portanto, as receitas das instalações da RBSE são "blindadas" e a revisão periódica das receitas das transmissoras é restrita ao âmbito das novas instalações (RBNI e RCDM) implantadas após 2000.

Baseada no critério revenue-cap, a revisão tarifária é realizada a cada quatro anos e nesta ocasião as RAPs das novas instalações são reposicionadas. No período entre as revisões as RAPs são reajustadas anualmente pelo IGPM.

A RAP das novas instalações autorizadas é a soma dos respectivos custos anuais dos ativos elétricos (CAAE) com os custos de administração e O\&M (CAOM), acrescidos dos encargos setoriais (PIS/COFINS, RGR, TFSEE, P\&D) e de uma parcela de ajuste. No ano da revisão tarifária os custos que compõem a RAP são posicionados em valores compatíveis com o equilíbrio da concessão e a modicidade tarifária: a remuneração dos ativos (parcela CAAE) é determinada de modo a garantir um retorno adequado ao capital prudentemente investido, enquanto os custos sob a rubrica CAOM são fixados em níveis considerados eficientes.

A definição da remuneração sobre o capital investido (parcela CAAE) é bastante complexa, conforme consta da Nota Técnica ANEEL nº 049/2007-SRE. Para calculá-la, é necessário definir o valor do investimento a ser remunerado (base de remuneração), a participação do capital próprio e de terceiros no capital total (estrutura de capital) e a taxa de retorno adequada a ser aplicada sobre o capital próprio e de terceiros.

No que se refere ao cálculo dos custos operacionais (CAOM) eficientes, o problema está na assimetria de informação entre o regulador e as concessionárias. Para mitigar os efeitos da assimetria de informação a ANEEL compara os custos operacionais das concessionárias com uma fronteira eficiente identificada por um modelo de análise envoltória de dados (DEA Data Envelopment Analysis), cujos resultados são apresentados na Nota Técnica ANEEL $\mathrm{n}^{\mathrm{o}} 182 / 2007-\mathrm{SRE}$.

Pesquisa Operacional, v.30, n.3, p.521-545, Setembro a Dezembro de 2010 
O propósito deste artigo consiste em discutir o modelo DEA utilizado pela ANEEL na primeira revisão tarifária das novas instalações (autorizadas) de transmissão e comparar os seus resultados com um modelo DEA alternativo, gerado a partir de uma adaptação do modelo DEA da ANEEL, em que são considerados os níveis de tensão das linhas de transmissão e as restrições aos multiplicadores.

O artigo está organizado em cinco seções, sendo a primeira esta breve introdução. A seguir, na seção 2, descreve-se o processo adotado pela ANEEL no cálculo dos custos operacionais eficientes das transmissoras de energia elétrica. Na seção 3, após uma revisão sobre os modelos clássicos de análise envoltória de dados, apresenta-se o modelo DEA utilizado pela ANEEL para calcular os coeficientes de eficiência das transmissoras. Os comentários ao modelo DEA utilizado pela ANEEL, a proposição de adaptações ao modelo e os resultados obtidos são apresentados na seção 4. Por fim, na seção 5 , são resumidas as principais conclusões do trabalho.

\section{Procedimento para o cálculo dos custos operacionais eficientes}

Este procedimento encontra-se descrito no Anexo III da Nota Técnica ANEEL n ${ }^{\circ}$ 182/2007, de 22 de junho de 2007, e segue as linhas gerais da Resolução ANEEL n 257/2007, na qual define-se o total dos custos de administração, operação e manutenção (CAOM) como a soma de três parcelas:

$$
\mathrm{CAOM}=\mathrm{CA}+\mathrm{COM}+\mathrm{CAIMI}
$$

Em (1), CA (Custos Administrativos) representa os custos de pessoal, materiais e serviços associados unicamente com a área administrativa; COM (Custos de Operação e Manutenção) envolve os custos de pessoal, materiais e serviços associados com as atividades de operação e manutenção das instalações de serviço e, por fim, CAIMI (Custo Anual das Instalações Móveis e Imóveis) refere-se aos custos com a infraestrutura de escritórios e transporte necessários para o apoio aos serviços de transmissão.

No reposicionamento da RAP das novas instalações autorizadas (NI), o regulador reconhece apenas a parcela eficiente dos custos de administração, operação e manutenção $\left(\mathrm{CAOM}_{\mathrm{NI}}\right)$ destas instalações. Basicamente, os custos operacionais eficientes para uma determinada concessionária $i$ são calculados pela seguinte fórmula:

$$
\mathrm{CAOM}_{\mathrm{NI}}(\mathrm{i})=\mathrm{CE}(\mathrm{i}) \times\left[\mathrm{COM}_{\mathrm{NI}}(\mathrm{i})+\mathrm{CAD}_{\mathrm{NI}}(\mathrm{i})\right]
$$

Em (2), CE(i) é o coeficiente de eficiência da concessionária $i$, determinado por meio de um modelo de Análise Envoltória de Dados (DEA); $\mathrm{COM}_{\mathrm{NI}}$ representa os valores correntes dos custos de operação e manutenção associados às novas instalações da concessionária e $\mathrm{CAD}_{\mathrm{NI}}$ denota os acréscimos nos custos administrativos (CA) e de instalações móveis e imóveis (CAIMI) associados às novas instalações.

Como os demonstrativos contábeis não informam as parcelas dos custos operacionais e administrativos relativos às novas instalações, estes custos são estimados por meio dos modelos descritos na Nota Técnica ANEEL nº 182/2007.

Em função das inconsistências nos demonstrativos contábeis das concessionárias, a ANEEL fixou a participação dos custos de O\&M no custo total (redes novas e existentes) em $60 \%$, o valor mediano desta relação observado nos dados enviados pelas concessionárias. 
Naturalmente, a participação dos custos administrativos corresponde a $40 \%$. O resultado deste critério é apresentado na Tabela 1.

Tabela 1 - Segregação dos custos totais.

\begin{tabular}{l|r|r|r}
\hline \multirow{2}{*}{ Concessionária } & \multicolumn{3}{|c}{$\begin{array}{c}\text { Custos no período de jul/2004 até jul/2005 (R\$): } \\
\text { rede existente e novas instalações }\end{array}$} \\
\cline { 2 - 4 } & Total & O\&M & $\begin{array}{c}\text { Administrativos } \\
\left(\mathrm{CAD}_{\text {TOTAL }}\right)\end{array}$ \\
\hline CEEE & 129.257 .412 & 77.554 .447 & 51.702 .965 \\
\hline Cemig & 115.327 .041 & 69.196 .225 & 46.130 .816 \\
\hline Chesf & 379.963 .954 & 227.978 .372 & 151.985 .582 \\
\hline Copel & 124.971 .021 & 74.982 .613 & 49.988 .408 \\
\hline Cteep & 561.312 .336 & 336.787 .401 & 224.524 .935 \\
\hline Eletronorte & 298.532 .638 & 179.119 .583 & 119.413 .055 \\
\hline Eletrosul & 208.100 .893 & 124.860 .534 & 83.240 .359 \\
\hline Furnas & 495.808 .521 & 297.485 .113 & 198.323 .408 \\
\hline
\end{tabular}

Fonte: Nota Técnica ANEEL nº 182/2007

Os ativos de transmissão são avaliados com base nas quantidades de quatro agregados físicos: quilometro de rede, capacidade de transformação (MVA), $\mathrm{n}^{\mathrm{o}}$ de transformadores e total de módulos de manobra (módulos de entrada de linha, conexão de transformador e interligação de barramentos). No modelo utilizado pela ANEEL, a participação das novas instalações no total de ativos é definida pela média ponderada das participações das NIs nos quatro agregados supracitados, cujos pesos são os coeficientes de regressão normalizados, obtidos pela regressão linear dos custos operacionais nas quantidades de cada agregado. As participações das NIs resultantes desta modelagem são apresentadas na Tabela 2. Aplicando estas participações aos custos de O\&M apresentados na Tabela 1 obtém-se a parcela COM $\mathrm{NI}_{\mathrm{N}}$ da equação (2).

Tabela 2 - Participação das NIs no total de ativos e O\&M das novas instalações.

\begin{tabular}{l|c|r}
\hline Concessionária & Participação das novas instalações no total de ativos $(\% \mathrm{NI})$ & $\mathrm{COM}_{\mathrm{NI}}(\mathrm{R} \$)$ \\
\hline CEEE & $10,77 \%$ & 8.350 .399 \\
\hline Cemig & $2,02 \%$ & 1.399 .385 \\
\hline Chesf & $6,76 \%$ & 15.417 .654 \\
\hline Copel & $8,51 \%$ & 6.378 .766 \\
\hline Cteep & $2,48 \%$ & 8.365 .846 \\
\hline Eletronorte & $9,45 \%$ & 16.921 .885 \\
\hline Eletrosul & $19,17 \%$ & 23.935 .964 \\
\hline Furnas & $10,98 \%$ & 32.652 .034 \\
\hline
\end{tabular}

Fonte: Nota Técnica ANEEL nº 182/2007 
Com relação aos custos administrativos admite-se que estes sejam fixos e, portanto, não aumentam com a expansão dos ativos da concessionária. Desta forma, na equação (2), o regulador reconhece a parcela $\mathrm{CAD}_{\mathrm{NI}}$ somente nos casos em que as novas instalações resultarem em incrementos de custos administrativos e CAIMI significativos em relação ao custo total. Conforme consta na metodologia descrita na Nota Técnica ANEEL n 182/2007, o regulador considera estes incrementos significativos quando as novas instalações representam mais de $5,69 \%$ do total de ativos da concessionária. Neste caso, a parcela $\mathrm{CAD}_{\mathrm{NI}}$ repassada aos custos eficientes é uma função do total dos custos administrativos e CAIMI da concessionária $\left(\mathrm{CAD}_{\mathrm{TOTAL}}\right.$ na Tabela 1$)$ e da participação das novas instalações no total de ativos (\%NI na Tabela 2$)$ :

$$
\begin{aligned}
& \mathrm{CAD}_{\mathrm{NI}}(\mathrm{i})=(\% \mathrm{NI}-5,69 \%) \times \mathrm{CAD}_{\mathrm{TOTAL}}(\mathrm{i}) / 100 \% \text { se } \% \mathrm{NI} \geq 5,69 \% \\
& \mathrm{CAD}_{\mathrm{NI}}(\mathrm{i})=0 \text { se } \% \mathrm{NI}<5,69 \%
\end{aligned}
$$

Por fim, na Tabela 3, são apresentados os custos operacionais eficientes das novas instalações, segregados em custos de O\&M e administrativos, juntamente com os coeficientes de eficiência obtidos com o auxílio do modelo DEA descrito na seção 3, a seguir. Conforme indicado na Tabela 2, na Cemig e na Cteep as estimativas das participações das novas instalações nos ativos totais (\%NI) são inferiores a 5,69\% e, portanto, para estas concessionárias atribuem-se valores nulos à parcela $\mathrm{CAD}_{\mathrm{NI}}$.

Tabela 3 - Custos operacionais eficientes das novas instalações $\left(\mathrm{CAOM}_{\mathrm{NI}}\right)$.

\begin{tabular}{l|c|r|r|r}
\hline \multirow{2}{*}{ Concessionária } & \multirow{2}{*}{$\begin{array}{c}\text { Coeficiente de } \\
\text { eficiência }(\mathrm{CE})\end{array}$} & \multicolumn{3}{|c}{ Custos operacionais eficientes $(\mathrm{R} \$)$} \\
\cline { 3 - 5 } & & $\begin{array}{c}\text { O\&M } \\
\left(\mathrm{CE} \times \mathrm{COM}_{\mathrm{NI}}\right)\end{array}$ & $\begin{array}{c}\text { Administrativos } \\
\left(\mathrm{CE}_{\mathrm{n}} \mathrm{CAD}\right.\end{array}$ & \multirow{2}{*}{ Total } \\
\hline CEEE & 0,9391 & 7.841 .518 & 2.463 .566 & 10.305 .085 \\
\hline Cemig & 0,9852 & 1.378 .665 & 0 & 1.378 .665 \\
\hline Chesf & 0,9414 & 14.513 .511 & 1.530 .432 & 16.043 .944 \\
\hline Copel & 1,0000 & 6.378 .766 & 1.406 .630 & 7.785 .396 \\
\hline Cteep & 0,8177 & 6.840 .956 & 0 & 6.840 .956 \\
\hline Eletronorte & 0,8000 & 13.537 .509 & 3.586 .380 & 17.123 .889 \\
\hline Eletrosul & 0,9354 & 22.388 .245 & 10.492 .979 & 32.881 .224 \\
\hline Furnas & 0,8952 & 29.232 .025 & 9.379 .905 & 38.611 .930 \\
\hline
\end{tabular}

Fonte: Nota Técnica ANEEL nº 182/2007

\section{Modelo DEA para avaliação dos coeficientes de eficiência}

\subsection{Por que DEA?}

A avaliação dos coeficientes de eficiência pode ser realizada por meio de modelos econométricos, em especial os modelos de fronteira estocástica ou SFA - Stochastic Frontier Analysis (Kumbhakar \& Lovell, 2000), ou por modelos de análise envoltória de dados (DEA), uma técnica baseada em programação linear proposta por Charnes et al. (1978).

O uso destas técnicas já é bastante difundido entre os agentes reguladores do setor elétrico, em particular na regulação dos serviços de distribuição e transmissão de eletricidade, conforme mostra a pesquisa realizada por Jasmab \& Pollit (2001). 
Os métodos DEA e SFA partem de pressupostos diferentes e apresentam vantagens e desvantagens de acordo com a aplicação em que são empregados e não há um método superior a priori. Contudo, o pequeno número de concessionárias de transmissão, apenas oito empresas, e o curto período de tempo analisado (2003/2005) produzem um painel com 24 observações, um conjunto de dados insuficiente para a estimação de modelos SFA. Nestas condições a ANEEL optou pela análise envoltória de dados.

Bogetoft \& Nielsen (2003) argumentam que a análise envoltória de dados constitui uma estrutura ideal para implementação de estratégias de regulação por comparação, pois além de avaliar índices de eficiência para cada concessionária, o modelo DEA identifica os melhores padrões de desempenho (benhchmark) que servem de referência para cada empresa, conferindo maior transparência ao processo regulatório.

\subsection{Análise envoltória de dados}

Uma tecnologia de produção transforma um vetor de insumos $X=\left\{x_{1}, \ldots, x_{s}\right\} \in R_{+}^{S}$ em um vetor de produtos $Y=\left\{y_{1}, \ldots, y_{m}\right\} \in R_{+}^{m}$ e pode ser representada pelo Conjunto de Possibilidades de Produção, definido como:

$$
T(X, Y)=\{(X, Y) \mid \text { é viável produzir Y a partir de } X\}
$$

Sob o enfoque de conservação de recursos (orientação input), a medida de eficiência técnica para uma unidade produtiva ou DMU - Decision Making Unit $(X, Y)$ é definida como a máxima contração do vetor de insumos (inputs) que permite produzir a mesma quantidade de produtos (outputs), ou seja:

$$
\text { Eficiência }=\operatorname{Min}\{\theta \mid(\theta X, Y) \in T(X, Y)\}
$$

A variável $\theta$ assume um valor entre 0 e 1, sendo que um valor unitário indica que não é possível reduzir a quantidade de insumos. Neste caso a DMU encontra-se na fronteira de eficiência e, portanto, é classificada como sendo tecnicamente eficiente (eficiência igual a $100 \%$ ). Caso contrário, a DMU é considerada tecnicamente ineficiente.

Com base nestes resultados e admitindo as hipóteses de rendimentos constantes de escala e tecnologia convexa Charnes et al. (1978) propuseram o primeiro modelo DEA, conhecido como CRS (Constant Return of Scale). Neste modelo a avaliação da eficiência é formulada como um problema de programação linear, em que a função objetivo é a máxima contração dos insumos e as restrições representam o conjunto de possibilidades de produção.

Posteriormente, Banker et al. (1984) adicionaram uma combinação linear convexa como restrição do modelo CRS, criando o modelo VRS (Variable Return of Scale) que contempla a possibilidade de rendimentos variáveis de escala. Uma característica do modelo VRS é que as DMU's que utilizam a menor quantidade de algum insumo ou produzem a maior quantidade de algum produto são consideradas tecnicamente eficientes.

$\mathrm{Na}$ Tabela 4, são apresentados os modelos DEA com orientação ao insumo (input oriented) nas versões CRS e VRS, onde $N$ é o total de DMUs (neste caso cada DMU é uma concessionária de transmissão) e o par $(X j, Y j)$ é o vetor com as quantidades dos $s$ insumos $\left(X_{j} \in R_{+}^{S}\right)$ e dos $m$ produtos $\left(Y_{j} \in R_{+}^{m}\right)$ na $j$-ésima DMU, $j=1, N$.

Pesquisa Operacional, v.30, n.3, p.521-545, Setembro a Dezembro de 2010 
Tabela 4 - Modelos DEA na formulação envelope e com orientação ao insumo.

\begin{tabular}{c|c}
\hline Modelo CRS & Modelo VRS \\
eficiência DMU $_{j 0}=\begin{array}{c}\text { Min } \\
\theta, \lambda\end{array} \quad \theta \quad$ (6) & eficiência $\mathrm{DMU}_{j 0}=\begin{array}{c}\text { Min } \\
\theta, \lambda\end{array} \quad \theta$ \\
s.a. $\quad \theta X_{j 0} \geq \sum_{j=1}^{N} \lambda_{j} X_{j}$ & s.a. $\quad \theta X_{j 0} \geq \sum_{j=1}^{N} \lambda_{j} X_{j}$ \\
$Y_{j 0} \leq \sum_{j=1}^{N} \lambda_{j} Y_{j}$ & $Y_{j 0} \leq \sum_{j=1}^{N} \lambda_{j} Y_{j}$ \\
$\lambda_{j} \geq 0 \forall j=1, \ldots, j 0, \ldots, N$ & $\sum_{j=1}^{N} \lambda_{j}=1$ \\
\multicolumn{2}{c}{$j 0$ é o índice da DMU avaliada, um número entre 1 e $N$} \\
\hline \multicolumn{2}{c}{$\lambda_{j} \geq 0 \forall j=1, \ldots, j 0, \ldots, N$} \\
\hline
\end{tabular}

A medida de eficiência $\theta$ é menor ou igual à unidade, indicando a máxima contração dos insumos mantendo fixas as quantidades dos produtos. Denotando a solução ótima dos modelos por $\left(\theta^{*}, \lambda^{*}{ }_{1}, \ldots, \lambda^{*}{ }_{N}\right)$, a DMU $j 0$ é eficiente, se e somente se, $\theta^{*}=1$ e todas as folgas nas restrições são nulas. Caso contrário, quando $\theta^{*}<1$ ou $\theta^{*=1}$, porém com folgas não nulas, a DMU $j 0$ é ineficiente. Se a DMU $j 0$ é ineficiente, algumas DMUs analisadas são tecnicamente eficientes. Neste caso, as DMUs eficientes estão associadas aos coeficientes $\lambda{ }_{j}>0 \forall j=1, N$ e formam o conjunto de referência (peer set) ou benchmarks para a DMU $j 0$.

\subsection{Formulação do modelo DEA utilizado pela ANEEL}

Basicamente, a formulação de um modelo DEA envolve a seleção das variáveis insumos (inputs) e produtos (outputs), a escolha da orientação do modelo e a escolha do tipo de retorno de escala (Golany \& Roll, 1989).

\subsubsection{Orientação do modelo DEA e variáveis inputs e outputs}

Os determinantes dos custos operacionais de uma concessionária de transmissão estão relacionados com o serviço de transporte de energia elétrica, mais especificamente, com a operação e a manutenção da disponibilidade das capacidades de transmissão dos seus ativos, representada pelas quantidades de quatro agregados físicos: capacidade de transformação (MVA), comprimento das linhas de transmissão $(\mathrm{km})$, quantidade de transformadores e quantidade de módulos de manobra. Estas variáveis caracterizam o porte da rede de transmissão, uma medida aproximada da capacidade disponível, o principal produto de uma transmissora. Para um determinado nível de produto, a transmissora deve produzi-lo com o menor custo possível.

Com base nas considerações acima e tendo como objetivo a obtenção de uma medida de eficiência que indique o quanto cada concessionária deverá reduzir seus custos operacionais, a ANEEL propõe um modelo DEA com orientação ao insumo, no qual o custo operacional 
total (O\&M + administrativos) é o único input e as quantidades dos quatro agregados físicos supracitados são os outputs. Conforme apresentado na Tabela 5, as correlações entre os outputs (y) e o custo operacional (x) são positivas, indicando que a hipótese de monotonicidade é satisfeita.

Tabela 5 - Matriz de correlações.

\begin{tabular}{l|ccccc}
\hline \multicolumn{1}{c|}{ Variáveis } & $\mathrm{x}$ & $\mathrm{y}_{1}$ & $\mathrm{y}_{2}$ & $\mathrm{y}_{3}$ & $\mathrm{y}_{4}$ \\
\hline Custos operacionais (x) & 1,0000 & & & & \\
Capacidade de transformação $\left(\mathrm{y}_{1}\right)$ & 0,8838 & 1,0000 & & & \\
Comprimento da rede $\left(\mathrm{y}_{2}\right)$ & 0,8406 & 0,8391 & 1,0000 & & \\
Quantidade de trafos $\left(\mathrm{y}_{3}\right)$ & 0,7954 & 0,7613 & 0,7698 & 1,0000 & \\
Quantidade de Módulos $\left(\mathrm{y}_{4}\right)$ & 0,5742 & 0,4493 & 0,6375 & 0,9077 & 1,0000 \\
\hline
\end{tabular}

As correlações positivas entre as variáveis outputs poderiam indicar alguma redundância, no entanto, é bom lembrar que estas variáveis estão associadas com produtos de naturezas distintas. Por exemplo, a capacidade de transformação está associada com o nível de potência que pode ser transmitida pela rede, enquanto o comprimento da rede está associado com sua extensão geográfica. A correlação positiva entre estas duas variáveis $(0,8391)$ deve-se a predominância da geração hidrelétrica no sistema elétrico brasileiro, que por ser distante dos principais núcleos consumidores implica em longas linhas de transmissão para transportar grandes blocos de energia das usinas até os centros de carga. Para minimizar as perdas de energia por aquecimento e aumentar a eficiência do transporte de grandes blocos de energia elétrica em longas distâncias, a transmissão de eletricidade é efetuada em tensões elevadas, por exemplo, $138 \mathrm{kV}, 230 \mathrm{kV}, 345 \mathrm{kV}, 500 \mathrm{kV}$ ou $765 \mathrm{kV}$, sendo que quanto maior o comprimento da linha, mais elevado deve ser o nível de tensão.

Porém, o valor ótimo para a tensão de transmissão situa-se muito acima dos níveis de tensão nos geradores de energia elétrica e dos níveis de tensão adequados para o consumo de eletricidade. Em função das limitações físicas e de isolamento elétrico, os geradores operam com tensões na faixa de $10 \mathrm{kV}$ a $30 \mathrm{kV}$. Por razões práticas e de segurança a distribuição de energia elétrica nos centros de carga não pode ser feita nos mesmos níveis de tensão da transmissão.

A geração e a distribuição de energia elétrica operam com faixas de tensão distintas da transmissão. A conexão destes sistemas é efetuada nas subestações, instalações elétricas que abrigam transformadores, equipamentos de corrente alternada que permitem a transferência de energia elétrica entre circuitos que operam com diferentes níveis de tensão. Por exemplo, as unidades geradoras injetam a sua energia na rede de transmissão através de transformadores elevadores, equipamentos que transformam a potência gerada aumentando a sua tensão (em geral menores que $30 \mathrm{kV}$ ) para os níveis de tensão da transmissão, com a consequente redução da corrente elétrica e, portanto, das perdas por aquecimento. De forma similar, na outra ponta do sistema de transmissão, a energia flui por transformadores abaixadores que reduzem a tensão de transmissão até os níveis adequados para a distribuição nos centros de carga. Ao longo de um sistema de transmissão podem existir outras subestações com a finalidade de controlar o fluxo de energia elétrica, por exemplo, redirecionando-o para outras linhas/sistemas de transmissão ou reunindo a energia elétrica proveniente de outras localidades. 
O transformador é o principal equipamento em uma subestação e os custos associados com a sua manutenção constituem importantes contribuições aos custos operacionais de uma transmissora. O total de transformadores é uma medida da disponibilidade de acessos ao sistema de transmissão, um parâmetro associado com o tamanho da demanda por energia elétrica e com o espalhamento espacial dos centros de carga, conforme indicado pelas correlações (Tabela 5) do número de transformadores com a capacidade de transformação e com o comprimento das linhas de transmissão. Além dos transformadores, as subestações incluem módulos necessários à sua operacionalidade, tais como entrada de linha, conexões de transformador e interligação de barramentos, cujas composições variam em função do nível de tensão, arranjo físico e porte da subestação. Por estarem associados com o total de transformadores, conforme indicado na Tabela 5, a quantidade de módulos contribui para os custos operacionais das transmissoras.

\subsubsection{DMUs analisadas}

Cooper et al. (2000) recomendam que o $\mathrm{n}^{\circ}$ de DMUs seja pelo menos o triplo do número de variáveis inputs e outputs. No entanto, só há oito transmissoras, o que limita a lista de insumos e produtos e a própria aplicação da abordagem DEA. A alternativa encontrada pela ANEEL para contornar esta restrição consiste em considerar cada transmissora, em um determinado ano, como uma DMU. Por exemplo, o desempenho de uma concessionária em 2005 é comparado com o desempenho de suas congêneres, ao longo dos três anos do painel de dados, e também com o seu próprio desempenho em 2003 e 2004. Esta abordagem possibilita a análise da evolução temporal de cada companhia, considerando que não houve mudança tecnológica ao longo do período analisado, uma hipótese plausível para a transmissão de energia elétrica. A mesma abordagem foi utilizada por Soares de Mello et al. (2003) na análise de eficiência das companhias aéreas brasileiras.

\subsubsection{Hipótese sobre o rendimento de escala}

Com relação ao rendimento de escala, a ANEEL adotou a hipótese de rendimentos não decrescentes de escala. No modelo DEA com rendimentos constantes de escala (CRS) uma DMU pode ser comparada com DMUs substancialmente maiores ou menores do que ela (Coelli et al., 2005). Para garantir a comparabilidade das DMUs recomenda-se que o modelo CRS seja aplicado em situações onde as concessionárias sejam do mesmo porte, uma situação não verificada no conjunto das oito empresas analisadas. Já no modelo DEA com rendimentos variáveis de escala (VRS), a restrição de convexidade $\lambda_{1}+\lambda_{2}+\ldots+\lambda_{\mathrm{N}}=1$ garante que as DMUs ineficientes sejam comparadas somente com as DMUs de mesmo tamanho ou nível de atividade (Coelli et al., 2005). No entanto, uma propriedade indesejável do modelo VRS é que as DMUs que apresentam os menores níveis de insumos ou os maiores níveis de produto, em pelo menos uma das variáveis, são classificadas como eficientes. Assim uma transmissora pode ser considerada eficiente pelo simples fato de operar a maior rede de transmissão, o que não significa necessariamente maior eficiência. 


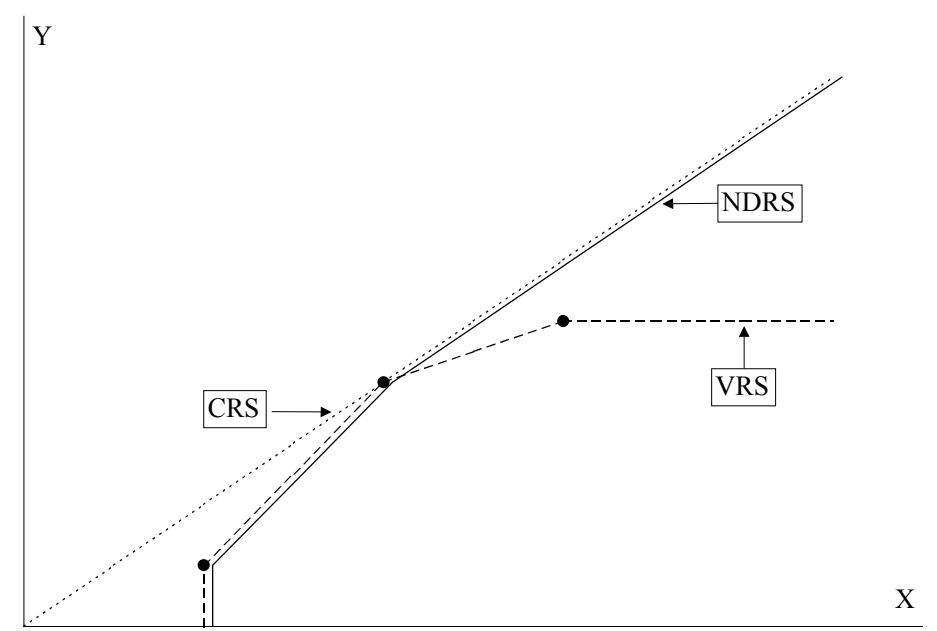

Figura 1 - Fronteiras de eficiência segundo diferentes hipóteses para o rendimento de escala.

Em função da hipótese de convexidade, a fronteira de eficiência estimada pelo modelo VRS é sempre caracterizada por rendimentos crescentes de escala nos menores níveis de atividade e por rendimentos decrescentes de escala nos maiores níveis de atividade, conforme indicado na Figura 1 para o caso de um insumo (X) e um produto (Y). Ressalta-se que esta propriedade do modelo DEA-VRS independe dos dados contidos na amostra de DMUs (Fernandes, 2004). A título de ilustração, no modelo DEA adotado pela ANEEL as transmissoras CEEE e Cemig localizam-se na região de rendimentos crescentes de escala, a Copel em 2003 apresenta rendimentos constantes de escala e as demais DMUs ocupam a região de rendimentos decrescentes de escala. Em resumo, na fronteira de eficiência gerada pelo modelo VRS os rendimentos não são crescentes ao longo de toda fronteira e a produtividade diminui à medida que o nível de atividade aumenta para além da escala ótima. Esta característica da fronteira VRS não atende aos objetivos da regulação econômica, em particular aos esquemas de regulação por incentivo, cuja proposta é construir mecanismos que estimulem os ganhos de produtividade. Para fins de um esquema de regulação por incentivo, e este é o objetivo da ANEEL, a alternativa ao modelo DEA-VRS é o modelo com rendimentos não decrescentes de escala ou DEA-NDRS (non-decreasing return to scale) uma variante do modelo VRS em que a restrição de convexidade $\lambda_{1}+\lambda_{2}+\ldots+\lambda_{N}=1$ é substituída pela desigualdade $\lambda_{1}+\lambda_{2}+\ldots+\lambda_{\mathrm{N}} \geq 1$, conforme indicado a seguir:

$$
\begin{array}{ll}
\text { eficiencia } \mathrm{DMU}_{j 0}= & \begin{array}{l}
\text { Min } \\
\theta, \lambda
\end{array} \\
\text { s.a. } & \theta X_{j 0} \geq \sum_{j=1}^{N} \lambda_{j} X_{j} \\
& Y_{j 0} \leq \sum_{j=1}^{N} \lambda_{j} Y_{j} \\
& \sum_{j=1}^{N} \lambda_{j} \geq 1 \\
& \lambda_{j} \geq 0 \forall j=1, \ldots, j 0, \ldots, N
\end{array}
$$


O objetivo da regulação econômica é incentivar a redução de custos, logo, as transmissoras devem ser encorajadas a operarem na escala ótima de operação definida pela fronteira CRS (Honkapuro, 2008). Porém, as transmissoras não são livres para escolherem suas escalas de operação, o que justificaria o uso do modelo VRS se este não fornecesse incentivos tímidos para a redução de custos $\left(\theta_{\mathrm{VRS}} \geq \theta_{\mathrm{CRS}}\right)$. A solução adotada pela ANEEL segue a estratégia usada por outros reguladores ao redor do mundo e consiste no modelo NDRS (Honkapuro, 2008). Tal modelo reconhece que as empresas menores (que operam na faixa de rendimentos crescentes de escala) operam em uma escala subótima e por esta razão não devem ser penalizadas com a imposição da fronteira CRS. Para estas empresas a fronteira é definida pelo modelo VRS. Por outro lado, para as empresas de maior porte (que operam na faixa de rendimentos decrescentes de escala), o modelo NDRS impõe a fronteira CRS como forma de incentivar a redução de custos destas empresas.

\subsection{Resultados do modelo DEA utilizado pela ANEEL}

A aplicação deste modelo ao painel de dados das transmissoras produziu os índices de eficiência apresentados na Tabela 6 . Em algumas concessionárias as estimativas dos coeficientes de eficiência são inferiores a $50 \%$ o que implicaria em absurdos cortes de receita (parcela da RAP) superiores à metade dos atuais níveis de custos operacionais. Para evitar esta situação e garantir o equilíbrio da concessão a ANEEL normalizou os coeficientes de eficiência para o mínimo de $80 \%$, i.e., a redução na receita associada aos custos operacionais pode atingir no máximo $20 \%$. Os valores normalizados apresentados na Tabela 6 são obtidos pela seguinte fórmula:

$$
C E(i)=\frac{(\text { Mediana }(i)-38,36)}{93,20-38,36} \cdot 20 \%+80 \% \quad i=1,8
$$

Em (9), os valores 38,36 e 93,20 são, respectivamente, a menor e a maior mediana na Tabela 6 .

Tabela 6 - Índices de eficiência (\%).

\begin{tabular}{l|c|c|c|c|c}
\hline Concessionária & 2003 & 2004 & 2005 & Mediana & Valor normalizado (CE) \\
\hline CEEE & 85,21 & 76,49 & 70,35 & 76,49 & 93,91 \\
\hline Cemig & 89,14 & 92,87 & 69,18 & 89,14 & 98,52 \\
\hline Chesf & 94,38 & 77,12 & 77,11 & 77,12 & 94,14 \\
\hline Copel & 100 & 82,42 & 93,20 & 93,20 & 100 \\
\hline Cteep & 49,71 & 43,22 & 42,60 & 43,22 & 81,77 \\
\hline Eletronorte & 42,63 & 38,36 & 34,86 & 38,36 & 80,00 \\
\hline Eletrosul & 83,69 & 75,05 & 75,47 & 75,47 & 93,54 \\
\hline Furnas & 69,54 & 64,48 & 53,79 & 64,48 & 89,52 \\
\hline
\end{tabular}

Fonte: Nota Técnica ANEEL no 182/2007-SRE 


\section{Comentários ao modelo DEA adotado pela ANEEL e proposta de adaptação}

\subsection{Concessionárias estaduais e federais}

As áreas de concessão das transmissoras estaduais (CEEE, Cemig, Copel e Cteep) estão confinadas aos limites geográficos de uma unidade da federação, enquanto nas transmissoras federais (Chesf, Furnas, Eletronorte e Eletrosul) as áreas de concessão abrangem basicamente as grandes regiões geográficas. Em função das diferenças na abrangência territorial pode-se esperar a existência de economias de densidade, cujos efeitos sobre a logística envolvida na operação e na manutenção dos ativos de transmissão contribuam para os custos operacionais das empresas. No entanto, conforme apresentado nos dados em anexo, apesar de atender apenas o Estado de São Paulo, a Cteep apresenta custos operacionais maiores que os observados nas empresas federais. A razão dos elevados custos operacionais da Cteep deve-se à sua grande capacidade de transformação, superada apenas por Furnas, e também ao elevado número de transformadores e módulos de manobra, em uma longa malha de transmissão. Tal fato indica que as diferenças na abrangência territorial das concessões podem ser desprezadas, porém o porte da concessionária de transmissão é relevante.

\subsection{Composição das redes por nível de tensão}

Um aspecto controverso do modelo DEA especificado pela ANEEL é o fato dele não considerar a composição dos ativos de transmissão por nível de tensão, uma característica com apreciáveis diferenças entre as empresas, conforme ilustrado na Tabela 7.

Tabela 7 - Comprimentos das redes de transmissão por empresa e por nível de tensão (2004).

\begin{tabular}{c|c|c|c|c|c|c|c|c|c}
\hline \multirow{2}{*}{$\begin{array}{c}\text { Tensão } \\
(\mathrm{kV})\end{array}$} & \multicolumn{7}{|c}{ Extensão das linhas de transmissão $(\mathrm{km})$} \\
\hline & CEEE & Cemig & Chesf & \multicolumn{1}{c}{ Copel } & Cteep & Elenorte & Elesul & Furnas & \multicolumn{1}{c}{ Total } \\
\hline 69 & $228(4 \%)$ & & $425(2 \%)$ & $1.110(16 \%)$ & $2(0,01 \%)$ & $709(7 \%)$ & $56(1 \%)$ & & $2.530(4 \%)$ \\
\hline 88 & & & & $58(1 \%)$ & $1.365(8 \%)$ & & & & $1.423(2 \%)$ \\
\hline 138 & $759(13 \%)$ & & $384(2 \%)$ & $3.996(59 \%)$ & $8.637(48 \%)$ & $692(7 \%)$ & $2.166(23 \%)$ & $2.204(12 \%)$ & $18.838(21 \%)$ \\
\hline 230 & $4.665(83 \%)$ & $752(15 \%)$ & $12.409(68 \%)$ & $1.438(21 \%)$ & $1.198(7 \%)$ & $5.409(54 \%)$ & $4.449(47 \%)$ & $1.949(10 \%)$ & $32.269(35 \%)$ \\
\hline 345 & & $1.957(40 \%)$ & & & $648(4 \%)$ & & & $5.687(30 \%)$ & $8.292(9 \%)$ \\
\hline 440 & & & & & $6.173(34 \%)$ & & & & $6.173(7 \%)$ \\
\hline 500 & & $2.172(44 \%)$ & $5.122(28 \%)$ & $161(2 \%)$ & & $3.257(32 \%)$ & $2.721(29 \%)$ & $4.549(24 \%)$ & $17.982(20 \%)$ \\
\hline $600(\mathrm{CC})$ & & & & & & & & $1.612(9 \%)$ & $1.612(2 \%)$ \\
\hline 750 & & & & & & & & $2.698(14 \%)$ & $2.698(3 \%)$ \\
\hline Total & 5.652 & 4.881 & 18.340 & 6.763 & 18.023 & 10.067 & 9.392 & 18.699 & 91.817 \\
\hline
\end{tabular}

Fonte: Associação Brasileira das Grandes Empresas de Transmissão de Energia Elétrica (ABRATE)

Nota: CC indica transmissão em corrente contínua

Para a ANEEL o efeito da tensão já estaria incluído na variável "capacidade de transformação", pois quanto maior o nível de tensão maior a capacidade da linha. Além disso, a ANEEL entende que os níveis de tensão são variáveis ambientais que afetam igualmente todas as empresas. Em linhas gerais, esta interpretação é a mesma apresentada por Dismukes et al. (1998) que com o auxílio de um modelo econométrico (função translog) confirmam a presença de fortes economias de escala na transmissão de energia elétrica. 
No entanto, na quantificação da base de remuneração, uma etapa importante no cálculo da receita anual permitida das concessionárias de transmissão, a ANEEL avalia os ativos da concessionária (unidades modulares de subestação e linhas de transmissão) com base em custos unitários de referência que variam com o nível de tensão, conforme definidos na Nota Técnica ANEEL nº 181/2007-SER (Tabela 8).

Tabela 8 - Custos de referência ANEEL para os equipamentos das subestações (R\$).

\begin{tabular}{|c|c|c|c|c|c|c|c|}
\hline \multirow{2}{*}{ Equipamentos } & \multicolumn{7}{|c|}{ Níveis de tensão (kV) } \\
\hline & $13,8 \mathrm{kV}$ & $34,5 \mathrm{kV}$ & $69 \mathrm{kV}$ & $138 \mathrm{kV}$ & $230 \mathrm{kV}$ & $345 \mathrm{kV}$ & $500 \mathrm{kV}$ \\
\hline Disjuntor & $67.742,57$ & $77.289,30$ & $76.036,88$ & $130.553,30$ & 336.572 .80 & $594.164,24$ & $1.399 .083,71$ \\
\hline $\begin{array}{c}\text { Chave } \\
\text { seccionadora }\end{array}$ & $8.029,72$ & $12.238,56$ & $24.096,05$ & $34.129,91$ & $60.565,46$ & $84.617,18$ & $157.349,00$ \\
\hline $\begin{array}{l}\text { Trafo de } \\
\text { corrente }\end{array}$ & & $8.073,31$ & $15.641,35$ & $28.554,95$ & $57.823,68$ & $74.085,26$ & $193.318,31$ \\
\hline $\begin{array}{c}\text { Trafo de } \\
\text { potencial } \\
\text { capacitivo }\end{array}$ & & & & $29.359,54$ & $50.627,12$ & $82.773,23$ & $78.622,40$ \\
\hline $\begin{array}{l}\text { Trafo de } \\
\text { potencial } \\
\text { indutivo }\end{array}$ & $2.659,14$ & $4.381,03$ & $15.671,46$ & $39.867,42$ & $50.850,52$ & & \\
\hline Pára-raios & 858,77 & $3.007,87$ & $3.676,27$ & $7.090,66$ & $16.544,63$ & $32.672,49$ & $56.688,13$ \\
\hline
\end{tabular}

Fonte: Nota Técnica ANEEL no 181/2007-SRE

Por exemplo, cada unidade modular de subestação (entrada de linha, conexão de transformador e interligação de barramentos) é composta por disjuntores, chaves seccionadoras, pára-raios e trafos de corrente e de potencial. A quantidade de equipamentos nos módulos depende do tipo de arranjo da subestação: disjuntor e meio, barra dupla, barra principal e transferência, barra simples e anel, sendo que o custo unitário de referência de cada equipamento é uma função crescente do nível de tensão, conforme ilustrado na Tabela 8.

Os custos unitários de referência ANEEL $(\mathrm{R} \$ / \mathrm{km})$ para as linhas de transmissão dependem do nível de tensão e de outras variáveis características da configuração da linha de transmissão: tipo de circuito (simples ou duplo), tipo de estrutura, tipo e número de condutores por circuito, tipo e número de cabos pára-raios e tipo de isolamento. Dependendo da configuração o custo unitário $(\mathrm{R} \$ / \mathrm{km})$ de uma linha de transmissão de menor tensão pode ser superior ao custo unitário de uma linha com maior nível de tensão, conforme ilustrado na Figura 2.

Não obstante, conforme apresentado na Tabela 9, a média e a mediana dos custos têm uma relação direta com o nível de tensão e, portanto, os investimentos requeridos também guardam uma relação direta com o nível de tensão da linha de transmissão.

Como os custos de operação e manutenção costumam ser uma proporção do investimento pode-se concluir que o nível de tensão relaciona-se com os custos operacionais e, portanto, é questionável tratar a tensão de transmissão como uma variável ambiental. 


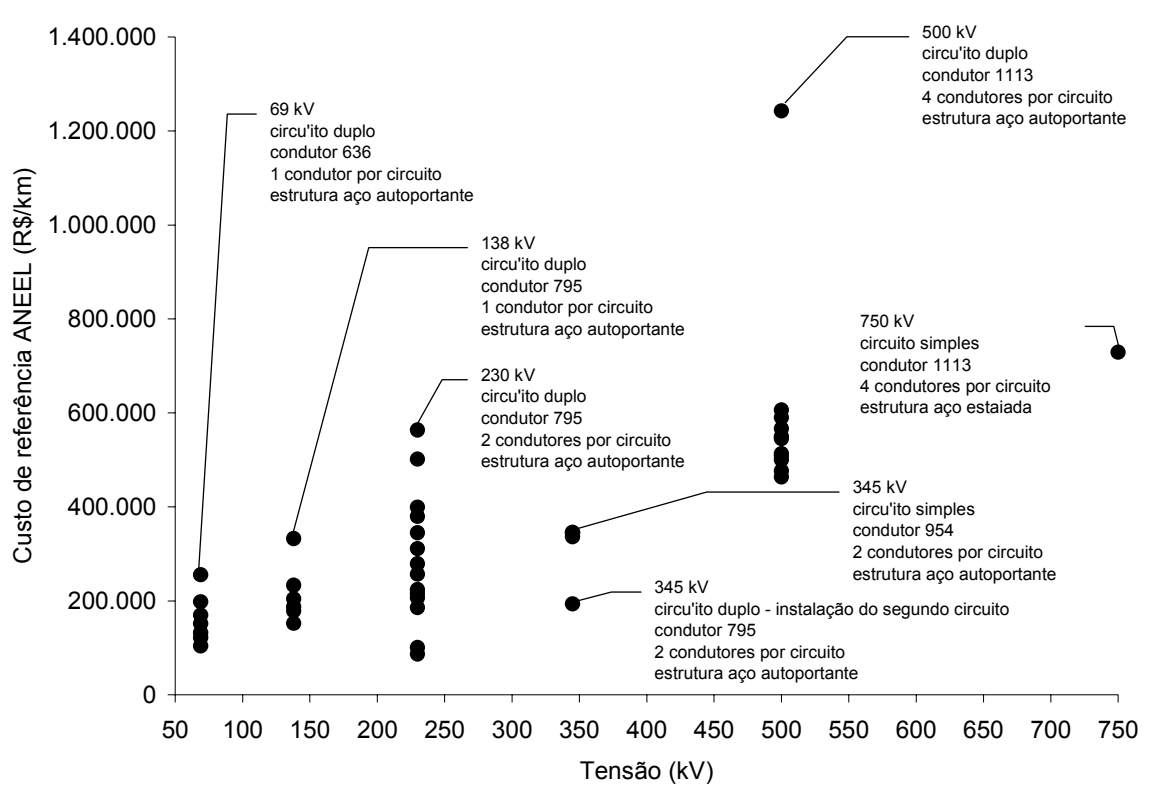

Fonte: Nota Técnica ANEEL no 181/2007

Figura 2 - Custos de referência $(\mathrm{R} \$ / \mathrm{km})$ ANEEL para as linhas de transmissão.

Tabela 9 - Custos de referência mínimos, médios e máximos por nível de tensão da linha.

\begin{tabular}{c|r|r|r|r}
\hline \multirow{2}{*}{ Tensão $(\mathrm{kV})$} & \multicolumn{4}{|c}{ Custos de referência ANEEL $(\mathrm{R} \$ / \mathrm{km})$} \\
\cline { 2 - 5 } & \multicolumn{1}{|c|}{ mínimo } & máximo & \multicolumn{1}{c}{ média } & \multicolumn{1}{c}{ mediana } \\
\hline 69 & $104.125,19$ & $255.583,37$ & $161.912,99$ & $151.708,03$ \\
\hline 138 & $152.089,13$ & $332.310,63$ & $214.595,39$ & $195.801,48$ \\
\hline 230 & $86.728,02$ & $563.717,21$ & $289.655,91$ & $267.876,43$ \\
\hline 345 & $193.717,52$ & $345.568,44$ & $305.278,80$ & $340.914,62$ \\
\hline 500 & $463.753,24$ & $1.242 .936,61$ & $596.743,03$ & $545.327,52$ \\
\hline 750 & $729.258,13$ & $729.258,13$ & $729.258,13$ & $729.258,13$ \\
\hline
\end{tabular}

Fonte: Valores obtidos com base na Nota Técnica ANEEL n $181 / 2007-\mathrm{SRE}$

Pollit (1994), diferentemente da ANEEL e de Dismukes et al. (1998), avalia a eficiência de transmissoras norte-americanas por meio de um modelo DEA em que um dos inputs é a capacidade de transmissão, definida pela soma acumulada dos produtos entre as tensões $(\mathrm{kV})$ e os comprimentos $(\mathrm{km})$ das $n$ linhas de transmissão de uma concessionária:

$$
k m k V=\sum_{i=1}^{n} k m_{i} \cdot k V_{i}
$$

Porém, conforme bem observado por Dismukes et al. (1998), a variável definida em (10) não é uma medida da capacidade de transmissão. De fato, a melhor medida da capacidade de transmissão é a potência dos transformadores em MVA. Não obstante, a proposta de Pollit (1994) 
fornece um caminho para introduzir o efeito do nível de tensão das linhas na avaliação da eficiência, pois pode ser interpretada como uma nova medida do comprimento das linhas, definida pela soma ponderada dos comprimentos, em que os níveis de tensão são os pesos. É importante observar que a escolha das ponderações das distâncias em (10) implica em assumir uma forma de diferenciar os custos dos níveis de tensão. Por exemplo, o modelo adotado pela ANEEL, ao considerar o comprimento total das linhas da concessionária, atribui um peso unitário a todas as distâncias sem diferenciar os efeitos dos níveis de tensão.

Ao invés de um esquema de pesos fixos definidos a priori como em (10), poder-se-ia considerar cada classe de tensão como sendo uma variável output do modelo DEA, cujos valores corresponderiam aos respectivos comprimentos totais dos circuitos. Neste caso, a ponderação das distâncias seria definida pelo próprio modelo DEA. No entanto, conforme ilustrado na Tabela 7, as transmissoras não operam em todos os níveis de tensão e por esta razão algumas destas variáveis assumiriam valores nulos em algumas DMUs e, portanto, esta alternativa foi descartada. A ponderação das distâncias pelos níveis de tensão em (10) implica em adotar um esquema de pesos que valoriza demasiadamente as linhas de maior tensão, mas que não guarda relação com os custos. Por exemplo, o peso atribuído às linhas de $345 \mathrm{kV}$ é cinco vezes o peso atribuído às linhas de $69 \mathrm{kV}(345 / 69=5)$, enquanto a razão entre os respectivos custos de referência medianos é aproximadamente 2,25. Ao invés de utilizar diretamente o nível de tensão como ponderador dos comprimentos das linhas, sugerese a utilização de um ponderador que incorpore as diferenças entre os custos de referência dos níveis de tensão. Assim, a variável $k m k V$ é redefinida como:

$$
k m k V=\sum_{i=1}^{n} k m_{i} \cdot\left(\frac{\text { custo de referência mediano no nivel } k V_{i}}{\text { custo de referência mediano no nivel } 69 \mathrm{kV}}\right)
$$

Na equação 11, os custos médios foram preteridos em relação aos custos medianos devido à existência de alguns outliers identificados na Figura 2.

A Nota Técnica ANEEL no 181/2007-SRE não apresenta os valores dos custos de referência para as tensões $88 \mathrm{kV}$ (Copel e Cteep), $440 \mathrm{kV}$ (Cteep) e $600 \mathrm{kV} \mathrm{CC} \mathrm{(Furnas).} \mathrm{Nestes} \mathrm{níveis}$ de tensão, os respectivos valores medianos dos custos de referência foram estimados com o auxílio da equação de regressão apresentada na Figura 3. Nos demais níveis de tensão são utilizados os custos medianos apresentados na Tabela 9. A seguir, na Tabela 10, são apresentadas as razões entre custos de referência que ponderam os comprimentos por nível de tensão na equação 11.

Tabela 10 - Ponderações dos comprimentos de linha por nível de tensão.

\begin{tabular}{c|c}
\hline Tensão $(\mathrm{kV})$ & Ponderação \\
\hline 69 & 1,0000 \\
\hline 88 & 1,0013 \\
\hline 138 & 1,2906 \\
\hline 230 & 1,7657 \\
\hline 345 & 2,2472 \\
\hline 440 & 3,0369 \\
\hline 500 & 3,5946 \\
\hline 600 & 3,9621 \\
\hline 750 & 4,8070 \\
\hline
\end{tabular}




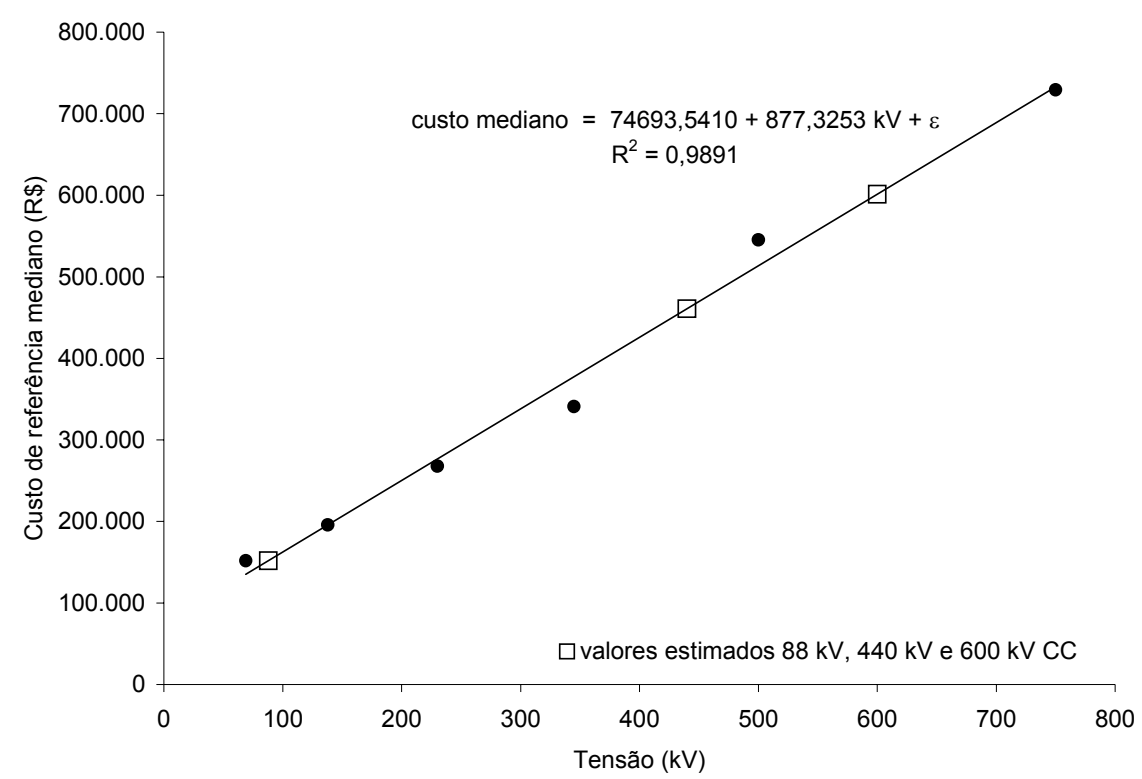

Figura 3 - Regressão dos valores medianos dos custos de referência nos níveis de tensão.

Na Tabela 7, os totais por concessionária em 2004, informados pela ABRATE, não conferem com os comprimentos das linhas nos dados em anexo, considerados pela ANEEL. Assim, visando manter a consistência com os dados utilizados pelo ANEEL, os comprimentos das linhas por nível de tensão, em cada concessionária e para o ano de 2004, foram calculados aplicando-se os percentuais indicados na Tabela 7 ao comprimento total das linhas da concessionária indicado nos dados em anexo. O mesmo procedimento foi aplicado aos anos de 2003 e 2005 e os resultado obtidos para a variável $k m K V$ são apresentados na Tabela 11, a seguir.

Tabela 11 - Variável $k m k V$.

\begin{tabular}{l|c|c|c}
\hline Concessionária & 2003 & 2004 & 2005 \\
\hline CEEE & 10.403 & 10.403 & 10.403 \\
\hline Cemig & 16.468 & 16.485 & 16.489 \\
\hline Chesf & 47.100 & 47.162 & 47.162 \\
\hline Copel & 10.269 & 10.285 & 10.285 \\
\hline Cteep & 35.319 & 35.371 & 35.371 \\
\hline Eletronorte & 17.700 & 17.700 & 17.700 \\
\hline Eletrosul & 23.196 & 23.899 & 24.012 \\
\hline Furnas & 54.397 & 54.919 & 55.882 \\
\hline
\end{tabular}

A variável $k m k V$ guarda uma forte correlação $(0,9403)$ com o comprimento da rede, maior que as correlações com o custo operacional $(0,7951)$ e com a capacidade de transformação $(0,8615)$. Por outro lado, são fracas as suas correlações com a quantidade de transformadores $(0,5799)$ e com a quantidade de módulos de manobra $(0,3707)$. Estas correlações indicam que a variável $\mathrm{kmkV}$ pode substituir o comprimento das linhas. 


\subsection{Restrições aos pesos}

A Nota Técnica ANEEL n $n^{\circ}$ 182/2007-SRE limita-se a apresentar os índices de eficiência das transmissoras em cada ano do período 2003-2005 e não registra as ponderações ou pesos atribuídos aos inputs e outputs pelo dual da versão envelope do modelo DEA conhecido como versão dos multiplicadores (Lins \& Meza, 2000). Uma investigação mais detalhada do modelo adotado pela ANEEL revela uma elevada frequência de pesos nulos atribuídos aos outputs. Tal fato compromete a avaliação realizada, pois apesar de contar com quatro outputs, a predominância de pesos nulos restringe a análise comparativa das empresas a um subconjunto menor de variáveis. Para evitar a atribuição de pesos nulos as seguintes restrições foram adicionadas aos produtos virtuais:

$$
\alpha_{i} \leq \frac{u_{i} \bar{y}_{i}}{u_{1} \bar{y}_{1}+u_{2} \bar{y}_{2}+u_{3} \bar{y}_{3}+u_{4} \bar{y}_{4}+u_{0}} \leq \beta_{i} \quad i=1,4
$$

onde $u_{i}, i=1,4$, são os pesos dos outputs; $\alpha_{i}$ e $\beta_{i}, i=1,4$, fixam os limites das restrições aos virtuais e $\bar{y}_{i}, i=1,4$, denotam os valores médios dos produtos, nas oito empresas ao longo do período de três anos: variável $k m k V$ definida em (11), capacidade de transformação (MVA), número de transformadores e número de módulos de manobra respectivamente.

Inspirado nos trabalhos de Thompson et al. (1990) e Zhu (1998), os limites das restrições aos virtuais foram definidos com base nos resultados da análise de componentes principais aplicada à matriz de correlações dos outputs, em particular na primeira componente principal definida pela combinação linear dos valores padronizados dos outputs:

$$
\begin{array}{ccc}
0,472\left(\frac{y_{1 j}-\bar{y}_{1}}{d p\left(y_{1}\right)}\right)+0,519\left(\frac{y_{2 j}-\bar{y}_{2}}{d p\left(y_{2}\right)}\right) & +0,547\left(\frac{y_{3 j}-\bar{y}_{3}}{d p\left(y_{3}\right)}\right)+0,457\left(\frac{y_{4 j}-\bar{y}_{4}}{d p\left(y_{4}\right)}\right) \\
k m k V & M V A \quad n^{o} \text { de transformadores } & n^{o} \text { de módulos }
\end{array}
$$

onde $y_{i j}$ denota o i-ésimo produto na j-ésima DMU, $\bar{y}_{i}$ é o valor médio das quantidades do i-ésimo output e $d p\left(y_{i}\right)$ o desvio padrão destas quantidades.

A primeira componente principal concentra cerca de $75 \%$ da variância total e os coeficientes da combinação linear (13) são todos positivos e têm a mesma ordem de grandeza, logo esta componente é um bom indicador do montante dos outputs disponibilizados por uma transmissora. Em cada DMU $j, j=1,24$, as contribuições dos outputs para o valor da primeira componente principal foram definidas pelos seguintes valores absolutos:

$$
\begin{array}{ll}
z_{1 j}=0,472\left|\frac{y_{1 j}-\bar{y}_{1}}{d p\left(y_{1}\right)}\right| & z_{2 j}=0,519\left|\frac{y_{2 j}-\bar{y}_{2}}{d p\left(y_{2}\right)}\right| \\
z_{3 j}=0,547\left|\frac{y_{3 j}-\bar{y}_{3}}{d p\left(y_{3}\right)}\right| & z_{4 j}=0,457\left|\frac{y_{4 j}-\bar{y}_{4}}{d p\left(y_{4}\right)}\right|
\end{array}
$$

Em termos relativos, as contribuições individuais dos outputs para a j-ésima DMU são calculadas pela seguinte fórmula:

$$
z_{i j} \cdot 100 \% /\left(z_{1 j}+z_{2 j}+z_{3 j}+z_{4 j}\right), \quad i=1,4 .
$$


Na Tabela 12 são apresentados os valores mínimos e máximos das contribuições $z_{i j}$ em cada variável e ao longo das 24 DMUs. Com base nestes valores foram definidos os seguintes limites para as restrições aos produtos virtuais: $\alpha_{\mathrm{i}}=0,04 \forall i=1,4, \beta_{1}=0,6 ; \beta_{2}=\beta_{3}=0,5 \mathrm{e}$ $\beta_{4}=0,4$.

Tabela 12 - Contribuições relativas dos outputs.

\begin{tabular}{c|c|c|c|c|}
\hline Contribuições & $k m k V$ & MVA & Transformadores & Módulos \\
\hline Máxima & $56 \%$ & $43 \%$ & $41 \%$ & $35 \%$ \\
\hline Mínima & $7 \%$ & $6 \%$ & $10 \%$ & $4 \%$ \\
\hline
\end{tabular}

\subsection{Resultados do modelo proposto e comparação com os resultados do modelo da ANEEL}

Os índices de eficiência obtidos pelo modelo DEA com a nova variável $k m k V$ e as restrições aos pesos são apresentados na Tabela 13, juntamente com os resultados do modelo original especificado pela ANEEL. As medianas dos índices de eficiência e os valores normalizados pela fórmula em (9) também são apresentadas na Tabela 13.

Tabela 13 - Índices de eficiência (\%).

\begin{tabular}{l|c|c|c|c|c|c}
\hline \multicolumn{7}{c}{ Resultados obtidos pelo modelo proposto } \\
\hline Concessionária & 2003 & 2004 & 2005 & Mediana & Valor normalizado (CE) & Ranking \\
\hline CEEE & 81,44 & 73,10 & 67,24 & 73,10 & 91,64 & 6 \\
\hline Cemig & 95,83 & 100 & 74,52 & 95,83 & 100 & 1 \\
\hline Chesf & 91,72 & 75,23 & 75,78 & 75,78 & 92,63 & 4 \\
\hline Copel & 100 & 82,38 & 93,15 & 93,15 & 99,02 & 2 \\
\hline Cteep & 55,14 & 48,25 & 47,56 & 48,25 & 82,50 & 7 \\
\hline Eletronorte & 45,95 & 41,44 & 37,66 & 41,44 & 80,00 & 8 \\
\hline Eletrosul & 81,72 & 73,02 & 73,61 & 73,61 & 91,83 & 5 \\
\hline Furnas & 86,85 & 81,01 & 66,79 & 81,01 & 94,55 & 3 \\
\hline Concessionária & 2003 & 2004 & 2005 & Mediana & Valor normalizado (CE) & Ranking \\
\hline CEEE & 85,21 & 76,49 & 70,35 & 76,49 & 93,91 & 4 \\
\hline Cemig & 89,14 & 92,87 & 69,18 & 89,14 & 98,52 & 2 \\
\hline Chesf & 94,38 & 77,12 & 77,11 & 77,12 & 94,14 & 3 \\
\hline Copel & 100 & 82,42 & 93,20 & 93,20 & 100 & 1 \\
\hline Cteep & 49,71 & 43,22 & 42,60 & 43,22 & 81,77 & 7 \\
\hline Eletronorte & 42,63 & 38,36 & 34,86 & 38,36 & 80,00 & 8 \\
\hline Eletrosul & 83,69 & 75,05 & 75,47 & 75,47 & 93,54 & 5 \\
\hline Furnas & 69,54 & 64,48 & 53,79 & 64,48 & 89,52 & 6 \\
\hline
\end{tabular}


As modificações implementadas no modelo proposto alteraram os índices de eficiência obtidos pela análise envoltória de dados, inclusive com alterações no ranking de eficiência das concessionárias, conforme indicado na Tabela 13. No modelo DEA adotado pela ANEEL, a Copel lidera o ranking das concessionárias, seguida de perto pela Cemig, enquanto no modelo proposto as posições se invertem e a Cemig passa a liderar o ranking, seguida pela Copel.

Um incremento no índice de eficiência significa um acréscimo na receita permitida da transmissora. Por outro lado, uma redução neste índice implica em perdas para a transmissora. Assim, conforme indicado pelos desvios na Tabela 14, o modelo DEA proposto implica em perdas para algumas transmissoras e ganhos para outras, sendo que a concessionária mais beneficiada é Furnas e as mais prejudicadas são a CEEE e a Eletrosul. As mudanças sugeridas no modelo DEA não modificaram o resultado para a Eletronorte, pois esta permanece com o menor índice de eficiência. Ressalta-se que o modelo DEA adotado pela ANEEL atribui pesos nulos para a maioria dos outputs e, portanto, os índices de eficiência acabam sendo calculados com base em apenas em um ou dois outputs e por isso os índices obtidos são superestimados e não refletem adequadamente a composição dos produtos. A inclusão das restrições aos pesos evita a atribuição de pesos nulos aos produtos e os índices de eficiência passam a depender dos níveis de todos os outputs considerados, mesmo daqueles que pouco contribuem para melhorar a posição da DMU avaliada.

Tabela 14 - Desvios entre os índices de eficiência (\%) obtidos pelos distintos modelos DEA.

\begin{tabular}{l|c|c|c}
\hline Concessionária & Modelo DEA proposto (A) & Modelo DEA ANEEL (B) & Desvios (A - B) \\
\hline CEEE & $91,64(6)$ & $93,91(4)$ & $-2,27$ \\
\hline Cemig & $100,00(1)$ & $98,52(2)$ & 1,48 \\
\hline Chesf & $92,63(4)$ & $94,14(3)$ & $-1,51$ \\
\hline Copel & $99,02(2)$ & $100,00(1)$ & $-0,98$ \\
\hline Cteep & $82,50(7)$ & $81,77(7)$ & 0,73 \\
\hline Eletronorte & $80,00(8)$ & $80,00(8)$ & 0 \\
\hline Eletrosul & $91,83(5)$ & $93,54(5)$ & $-1,71$ \\
\hline Furnas & $94,55(3)$ & $89,52(6)$ & 5,03 \\
\hline
\end{tabular}

Nota: Ranking entre parêntesis

A consideração dos níveis de tensão das linhas por meio da variável $k m k V$ fornece uma medida mais justa do nível de eficiência de Furnas, pois reconhece o fato desta ser a única concessionária de transmissão do SIN a operar sistemas de $600 \mathrm{kV} \mathrm{CC} \mathrm{e} 750 \mathrm{kV}$. Ressalta-se que estes sistemas são estratégicos para o país, pois conectam a hidrelétrica de Itaipu Binacional ao SIN e transportam cerca de $20 \%$ da energia consumida no Brasil (www.itaipu.gov.br).

Substituindo os coeficientes de eficiência, na Tabela 3, pelos novos índices e recalculando os custos de O\&M e administrativos eficientes obtém-se novos valores apresentados na Tabela 15, onde pode-se observar que as considerações apresentadas neste trabalho afetam significativamente a receita permitida de Furnas. 
Tabela 15 - Custos operacionais eficientes das novas instalações $\left(\mathrm{CAOM}_{\mathrm{NI}}\right)$.

\begin{tabular}{|c|c|c|c|c|c|}
\hline \multirow[b]{2}{*}{ Concessionária } & \multirow[b]{2}{*}{$\begin{array}{l}\text { Coeficiente } \\
\text { de eficiência } \\
\text { (CE) }\end{array}$} & \multicolumn{4}{|c|}{ Custos operacionais eficientes ( $\mathrm{R} \$$ ) } \\
\hline & & $\begin{array}{c}\mathrm{O} \& \mathrm{M} \\
\left(\mathrm{CE} \times \mathrm{COM}_{\mathrm{NI}}\right)\end{array}$ & $\begin{array}{c}\text { Administrativos } \\
\left(\mathrm{CE} \times \mathrm{CAD}_{\mathrm{NI}}\right)\end{array}$ & Total & $\begin{array}{c}\text { Desvio em } \\
\text { relação ao } \\
\text { resultado obtido } \\
\text { pela ANEEL } \\
\text { (Tabela 3) }\end{array}$ \\
\hline CEEE & 0,9164 & 7.652 .617 & 2.404 .114 & 10.056 .731 & -248.354 \\
\hline Cemig & 1 & 1.399 .385 & 0 & 1.399 .385 & 20.720 \\
\hline Chesf & 0,9263 & 14.281.293 & 1.505 .876 & 15.787 .168 & -256.776 \\
\hline Copel & 0,9902 & 6.316 .051 & 1.392 .800 & 7.708 .852 & -76.544 \\
\hline Cteep & 0,8250 & 6.902 .079 & 0 & 6.902 .079 & 61.123 \\
\hline Eletronorte & 0,8000 & 13.537 .509 & 3.586 .380 & 17.123 .889 & 0 \\
\hline Eletrosul & 0,9183 & 21.980 .717 & 10.301 .308 & 32.282 .026 & -599.198 \\
\hline Furnas & 0,9455 & 30.872 .829 & 9.907 .054 & 40.779 .883 & 2.167 .953 \\
\hline
\end{tabular}

Na Tabela 15, pode-se observar também que o total dos ganhos nas empresas beneficiadas supera o total das perdas nas empresas prejudicadas, indicando que o modelo com a variável $k m k V$, acompanhado das restrições aos pesos, tende a beneficiar o setor de transmissão como um todo.

A seguir, na Tabela 16, são apresentados os resultados obtidos pelo modelo proposto considerando-se três diferentes regimes para o rendimento de escala: NDRS, VRS e CRS. Uma simples comparação dos resultados revela que as DMUs CEEE (2003, 2004, 2005), Cemig $(2003,2005)$ e Eletronorte $(2003,2004,2005)$ operam com rendimentos crescentes de escala, Cemig (2004) e Copel (2003) operam com rendimentos constantes de escala e as demais DMUs operam com rendimentos decrescentes de escala.

Tabela 16 - Índices de eficiência (\%).

\begin{tabular}{l|c|c|c|c|c|c}
\hline \multicolumn{7}{c}{ Resultados obtidos com o output kmkV-Modelo NDRS } \\
\hline Concessionária & 2003 & 2004 & 2005 & Mediana & Valor normalizado (CE) & Ranking \\
\hline CEEE & 81,44 & 73,10 & 67,24 & 73,10 & 91,64 & 6 \\
\hline Cemig & 95,83 & 100 & 74,52 & 95,83 & 100 & 1 \\
\hline Chesf & 91,72 & 75,23 & 75,78 & 75,78 & 92,63 & 4 \\
\hline Copel & 100 & 82,38 & 93,15 & 93,15 & 99,02 & 2 \\
\hline Cteep & 55,14 & 48,25 & 47,56 & 48,25 & 82,50 & 7 \\
\hline Eletronorte & 45,95 & 41,44 & 37,66 & 41,44 & 80,00 & 8 \\
\hline Eletrosul & 81,72 & 73,02 & 73,61 & 73,61 & 91,83 & 5 \\
\hline Furnas & 86,85 & 81,01 & 66,79 & 81,01 & 94,55 & 3 \\
\hline
\end{tabular}

(continua...) 
Tabela 16 (continuação).

\begin{tabular}{l|c|c|c|c|c|c}
\hline \multicolumn{7}{c}{ Resultados obtidos com o output kmkV-Modelo VRS } \\
\hline Concessionária & 2003 & 2004 & 2005 & Mediana & Valor normalizado (CE) & Ranking \\
\hline CEEE & 81,44 & 73,10 & 67,24 & 73,10 & 91,64 & 6 \\
\hline Cemig & 95,83 & 100 & 74,52 & 95,83 & 100 & 1 \\
\hline Chesf & 100 & 82,57 & 83,88 & 83,88 & 95,61 & 4 \\
\hline Copel & 100 & 82,40 & 93,18 & 93,18 & 99,03 & 3 \\
\hline Cteep & 78,79 & 69,20 & 68,23 & 69,20 & 90,21 & 7 \\
\hline Eletronorte & 45,95 & 41,44 & 37,66 & 41,44 & 80,00 & 8 \\
\hline Eletrosul & 82,96 & 74,40 & 75,12 & 75,12 & 92,38 & 5 \\
\hline Furnas & 100 & 93,24 & 77,28 & 93,24 & 99,05 & 2 \\
\hline \multicolumn{7}{|c|}{ Resultados obtidos com o output kmkV-Modelo CRS } \\
\hline Concessionária & 2003 & 2004 & 2005 & Mediana & Valor normalizado (CE) & Ranking \\
\hline CEEE & 73,65 & 66,12 & 60,91 & 66,12 & 89,20 & 6 \\
\hline Cemig & 95,36 & 100 & 74,51 & 95,36 & 100 & 1 \\
\hline Chesf & 91,72 & 75,23 & 75,78 & 75,78 & 92,77 & 4 \\
\hline Copel & 100 & 82,38 & 93,15 & 93,15 & 99,19 & 2 \\
\hline Cteep & 55,14 & 48,25 & 47,56 & 48,25 & 82,61 & 7 \\
\hline Eletronorte & 45,61 & 41,19 & 37,43 & 41,19 & 80,00 & 8 \\
\hline Eletrosul & 81,72 & 73,02 & 73,61 & 73,61 & 91,97 & 5 \\
\hline Furnas & 86,85 & 81,01 & 66,79 & 81,01 & 94,70 & 3 \\
\hline
\end{tabular}

A seguir, na Figura 4, as medianas dos índices de eficiência apresentadas na Tabela 16 são dispostas em um gráfico que ilustra como a decisão acerca do tipo de rendimento de escala afeta significativamente as metas de redução de custos para a CEEE, Chesf, Cteep e Furnas. Entre estas quatro empresas, a CEEE é a única que opera com rendimentos crescentes de escala, enquanto as outras três operam com rendimentos decrescentes de escala.

Visando a criação de um mecanismo de regulação que incentive os ganhos de produtividade, a ANEEL adotou a fronteira NDRS. Conforme indicado na Figura 4 e na Tabela 16, a fronteira NDRS implica em metas de redução de custos operacionais para a Chesf, Cteep e Furnas que são mais rigorosas do que as estabelecidas pelo modelo DEA-VRS. No entanto, deve-se ressaltar que estas três empresas são as maiores transmissoras do SEB e por isso operam na região com rendimentos decrescentes de escala, pois, em função da hipótese de convexidade, a fronteira de eficiência VRS é sempre caracterizada por rendimentos decrescentes de escala nos maiores níveis de atividade, independentemente dos dados contidos na amostra (Fernandes, 2004). Por esta razão, os índices de eficiência obtidos pelo modelo DEA-VRS para estas três empresas podem estar superestimados.

Por fim, destaca-se que o modelo DEA NDRS proposto gera resultados próximos ao modelo CRS, o que atende o objetivo da regulação econômica que é incentivar a redução de custos e encorajar as transmissoras a operarem na escala ótima de operação (Honkapuro, 2008). 


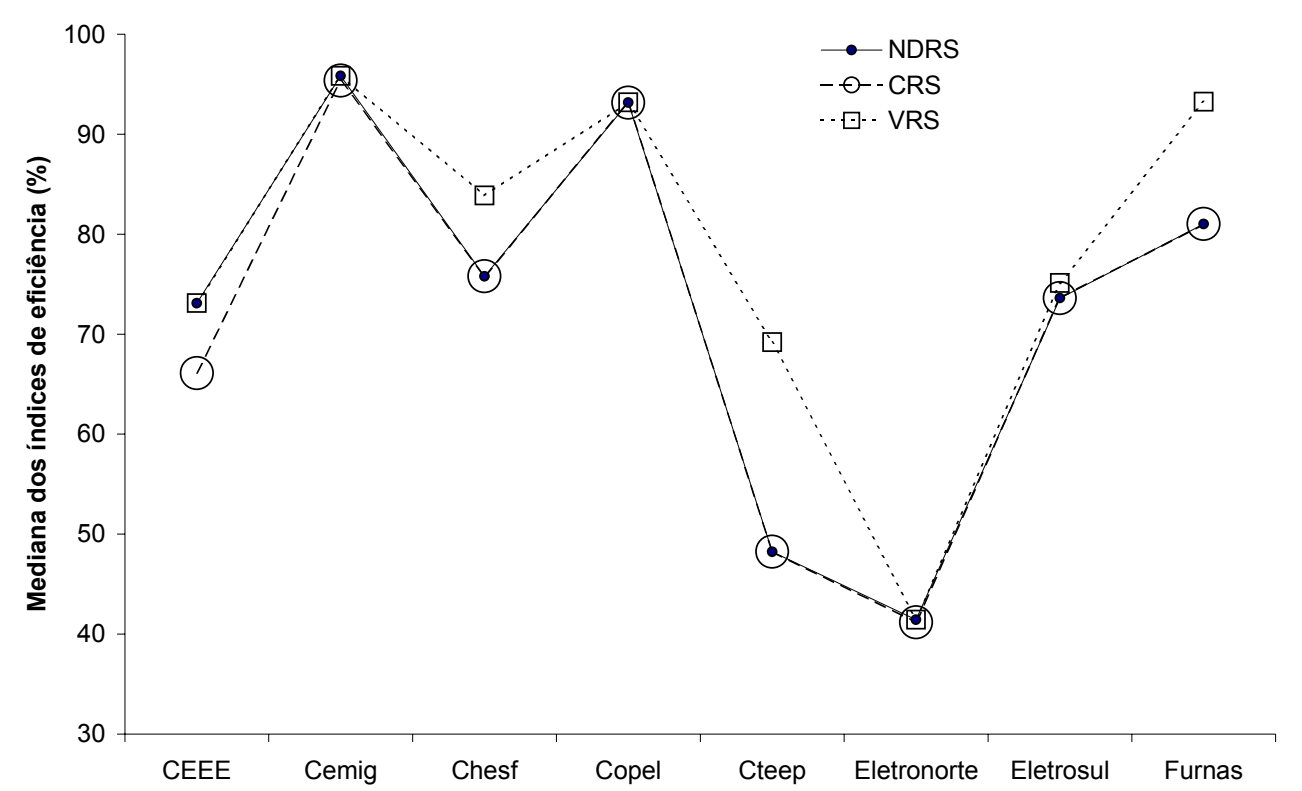

Figura 4 - Medianas dos índices de eficiência segundo diferentes tipos de rendimentos de escalas.

\section{Conclusão}

Para avaliar os custos operacionais eficientes das transmissoras, um dos itens da receita permitida das concessionárias de transmissão, a ANEEL utiliza um modelo de análise envoltória de dados (DEA), orientado ao input, tendo como insumo o custo operacional e como produtos quatro agregados físicos: capacidade de transformação, comprimento das linhas, número de transformadores e número de módulos.

Apesar de incluir os principais diretores dos custos operacionais das transmissoras, o modelo DEA formulado pela ANEEL não contempla os efeitos dos níveis de tensão das linhas de transmissão, admitindo que estes efeitos sejam os mesmo em todas as concessionárias. Porém, dado que usualmente os custos operacionais correspondem a uma parcela do investimento, a hipótese adotada pela ANEEL parece pouco plausível, pois os níveis de tensão das linhas guardam uma relação direta com o investimento e, portanto, afetam os custos operacionais.

Inspirado em Pollit (1994), este trabalho retoma esta questão e propõe uma adaptação do modelo DEA adotado pela ANEEL em que o comprimento de rede, um dos outputs do modelo DEA, é modificado para incluir os efeitos dos níveis de tensão. Além desta substituição de variáveis propõe-se a inclusão de um conjunto de restrições aos produtos virtuais como forma de evitar a atribuição de pesos nulos aos outputs, um problema encontrado no modelo DEA adotado pela ANEEL e que compromete toda a avaliação dos índices de eficiência das concessionárias de transmissão. A adaptação proposta promoveu alterações nos índices de eficiência e no ranking das transmissoras, indicando a significância das adaptações sugeridas.

As divergências entre os resultados do modelo adaptado e os obtidos pela ANEEL têm importantes implicações para os custos operacionais eficientes das novas instalações de 
transmissão e representam perdas ou ganhos para as transmissoras. Os resultados apresentados mostram que a não consideração do nível de tensão penaliza sobremaneira a concessionária de transmissão responsável pela operação das linhas que transportam a energia gerada na usina de Itaipu. Portanto, é questionável a premissa adotada pela ANEEL de que a tensão de transmissão seja uma variável ambiental que afete igualmente todas as empresas transmissoras.

\section{Referências Bibliográficas}

(1) ANEEL (2000). Resolução, $\mathrm{n}^{\circ}$ 166/2000.

(2) ANEEL (2000). Resolução, $n^{\circ}$ 167/2000.

(3) ANEEL (2006). Nota Técnica, $\mathrm{n}^{\circ} 068 / 2006-\mathrm{SRT}$.

(4) ANEEL (2007). Nota Técnica, $n^{\circ} 049 / 2007-S R E$.

(5) ANEEL (2007). Nota Técnica, $\mathrm{n}^{\circ}$ 181/2007-SRE.

(6) ANEEL (2007). Nota Técnica, $n^{\circ}$ 182/2007-SRE.

(7) ANEEL (2007). Resolução, nº 257/2007.

(8) Banker, R.D.; Charnes, A. \& Cooper, W.W. (1984). Some Models for Estimating Technical and Scale Inefficiencies. Management Science, 39.

(9) Bogetoft, P. \& Nielsen, K. (2003). DEA based yardstick competition in natural resource management. In: Recent Accomplishments in Applied Forest Economics Research [edited by F. Helle, N. Strange and L. Wichmann], Kluwer Academic Publisher.

(10) Charnes, A.; Cooper, W.W. \& Rhodes, E. (1978). Measuring the Efficiency of Decision Making Units. European Journal of Operational Research, 2.

(11) Coelli, T.J.; Rao, D.S.P.; O'donnell, C.J. \& Battese, G.E. (2005). An introduction to efficiency and productivity analysis. $2^{\text {nd }}$ edition, Springer.

(12) Cooper, W.W.; Seiford, L.M. \& Tone, K. (2000). Data Envelopment Analysis, A Comprehensive Text with Models Applications, Reference and DEA-Solver Software. Kluwer Academic Publishers.

(13) Dismukes, D.E; Cope III, R.F. \& Mesyanzhinov, D. (1998). Capacity and economies of scale in electric power transmission. Utilities Policy, 7, 155-162.

(14) Fernandes, P. (2004). When assumptions go unquestioned. Disponível em $<\mathrm{http} / / /$ www.reckon.co.uk/ReckonDEANov2004.pdf $>$. Acessado em 23/10/2007.

(15) Golany, B. \& Roll, Y. (1989). An application procedure for DEA. Omega, 17(3), 237-250.

(16) Honkapuro, S. (2008). Performance Benchmarking and Incentive Regulation Considerations of Directing Signals for Electricity Distribution Companies. Thesis, Lappeenranta University of Technology, Lappeenranta, Finland.

(17) Jasmab, T. \& Pollit, M. (2001). Benchmarking and regulation: international electricity experience. Utilities Policy, 9(3), 107-130.

(18) Kumbhakar, S.C. \& Lovell, C.A.K. (2000). Stochastic Frontier Analysis. Cambridge University Press.

(19) Lins, M.P.E. \& Meza, L.A. (2000). Análise Envoltória de Dados e Perspectivas de Integração no Ambiente de Apoio à Decisão. COPPE/UFRJ, Rio de Janeiro. 
(20) Pollit, M.G. (1994). Productivity efficiency in electricity transmission and distribution systems. University of Oxford Applied Economics Discussion Paper, Paper Series, n.161.

(21) Soares de Mello, J.C.C.B.; Meza, L.A.; Gomes, E.G.; Serapião, B.P. \& Lins, M.P.E. (2003). Análise de envoltória de dados no estudo da eficiência e dos benchmarks para companhias aéreas brasileiras. Pesquisa Operacional, 23(2), 325-345.

(22) Thompson, R.G.; Langemeier, L.N.; Lee, C.; Lee, E. \& Thrall, R.M. (1990). The role of multiplier bounds in efficiency analysis with application to Kansas farming. Journal of Econometrics, 46, 93-108.

(23) Zhu, J. (1998). Data envelopment analysis vs. principal component analysis: An illustrative study of economic performance of Chinese cities. European Journal of Operational Research, 111, 50-61.

Anexo - Dados de entrada do modelo DEA.

\begin{tabular}{c|c|c|c|c|c|c}
\hline Concessionária & Ano & Custo total (R\$) & $\begin{array}{c}\text { Capacidade de } \\
\text { transformação } \\
\text { (MVA) }\end{array}$ & $\begin{array}{c}\text { Comprimento } \\
\text { da rede }(\mathrm{km})\end{array}$ & $\begin{array}{c}\text { Quantidade } \\
\text { de trafos }\end{array}$ & $\begin{array}{c}\text { Quantidade } \\
\text { de módulos }\end{array}$ \\
\hline CEEE & 2005 & 146.580 .493 & 6.993 & 6.226 & 169 & 906 \\
CEMIG & 2005 & 149.067 .203 & 14.644 & 5.946 & 124 & 516 \\
CHESF & 2005 & 381.365 .832 & 29.039 & 20.972 & 383 & 1.656 \\
COPEL & 2005 & 110.822 .217 & 18.343 & 7.366 & 290 & 1.072 \\
CTEEP & 2005 & 602.352 .315 & 45.292 & 18.301 & 565 & 1.936 \\
ELENOR & 2005 & 313.485 .008 & 14.539 & 7.795 & 161 & 574 \\
ELESUL & 2005 & 204.500 .605 & 18.092 & 11.007 & 130 & 488 \\
FURNAS & 2005 & 563.816 .133 & 53.944 & 19.119 & 332 & 723 \\
\hline CEEE & 2004 & 134.819 .251 & 6.993 & 6.225 & 169 & 903 \\
CEMIG & 2004 & 111.047 .924 & 14.644 & 5.946 & 124 & 515 \\
CHESF & 2004 & 381.289 .811 & 28.239 & 20.972 & 379 & 1.638 \\
COPEL & 2004 & 125.313 .032 & 18.343 & 7.366 & 290 & 1.072 \\
CTEEP & 2004 & 593.770 .676 & 45.292 & 18.301 & 565 & 1.935 \\
ELENOR & 2004 & 284.907 .231 & 14.539 & 7.795 & 161 & 574 \\
ELESUL & 2004 & 204.692 .870 & 17.924 & 10.955 & 128 & 470 \\
FURNAS & 2004 & 454.019 .498 & 52.069 & 18.749 & 325 & 716 \\
\hline CEEE & 2003 & 121.020 .860 & 6.993 & 6.225 & 169 & 903 \\
CEMIG & 2003 & 115.688 .863 & 14.419 & 5.940 & 123 & 503 \\
CHESF & 2003 & 311.158 .173 & 27.839 & 20.944 & 375 & 1.624 \\
COPEL & 2003 & 103.125 .259 & 18.343 & 7.355 & 290 & 1.071 \\
CTEEP & 2003 & 515.507 .003 & 44.542 & 18.274 & 562 & 1.917 \\
ELENOR & 2003 & 256.378 .055 & 14.416 & 7.795 & 158 & 569 \\
ELESUL & 2003 & 178.155 .519 & 17.616 & 10.633 & 124 & 456 \\
FURNAS & 2003 & 420.964 .595 & 52.069 & 18.571 & 325 & 712 \\
\hline FU & & & & \\
\hline
\end{tabular}

Fonte: Nota Técnica ANEEL no $182 / 2007-$ SRE 